\title{
Design and Modeling of Multi-Winding Transformers interfacing Inverters and Mains
}

\author{
Antonino Di Gerlando, Khaled ElShawarby, Giovanni Maria Foglia, Roberto Perini
}

\begin{abstract}
The paper concerns the study of multi-winding transformers (MWT), with inverter fed LV primary windings and one MV secondary winding connected to the mains. Typical application fields are medium power WECSs, consisting of modular components (multi-module generator and transformer). The transformer design and modeling aspects are considered, and its performances are estimated, considering inverter command parameters, current waveforms, copper and core losses, accounting for the effects due to harmonics.
\end{abstract}

Index Terms-multi-winding transformers, transformer design, transformer model, inverter fed transformer losses.

\section{INTRODUCTION}

$\mathrm{T}$ he increasing diffusion of WECSs (Wind Energy Conversion Systems) for on- and off-shore plants brought to a number of conversion chain solutions: DFIGs or PM machines [1, 2], with radial or axial flux disposition [3], geared or direct drive generators [4], full or slip power electronic converters [5], multi-phase machines $[6,7]$, multi-module systems [8].

The reasons that move to develop these different solutions can be resumed as follows:

- increasing the conversion chain efficiency;

- ensuring a good operation waveform quality;

- sharing the turbine power in order to limit the module rating and to increase the system reliability.

One of the possible solutions for the generator side subsystem is drawn in the left part of fig.1: the generator is a modular machine, for example, but not necessarily, a PM axial flux machine, with a number of stator modules [9].

The multi-module generator side subsystem, separately analyzed [10], exhibits the following main advantages:

- limitation of module voltage and current rating;

- magnetic decoupling among three-phase modules;

- possible sequential command of the modular inverters;

- use of standard IGBTs and of standard two-level inverters, thanks to the LV (Low Voltage) level of the dc link, with parallel topology.

Of course, the LV dc side parallel configuration is more suited for back-to-back dispositions (typical of on-shore plants), because of the high current level.

In this paper, the modularity concept is analyzed for the mains side subsystem, consisting of a number of dc paralleled inverters, and a Multi-Winding Transformer (MWT) with a number of primary LV windings equal to the number of inverters and one MV (Medium Voltage) secondary winding

Authors are with the Department of Energy at Politecnico di Milano, via La Masa 34, 20156 Milano -Italy

e-mails: antonino.digerlando@polimi.it, khaled.elshawarby@mail.polimi.it, gianmaria.foglia@polimi.it, roberto.perini@polimi.it faced to the mains.

In principle, this solution has the following advantages:

- power sharing among identical two-level standard inverters;

- superposition of the primary current ripples, with lower distortion of the secondary current;

- possibility to segregate a faulted system portion, ensuring the system operation continuity at reduced power.

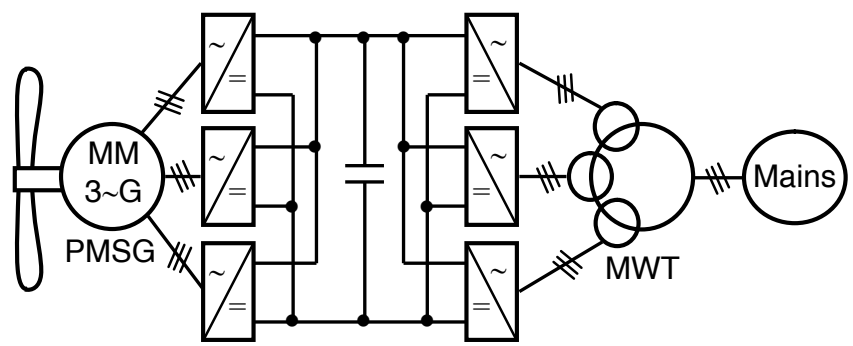

Fig. 1. Scheme of a multi-module wind energy system consisting of: a multi three-phase module PM synchronous generator; three generator-side inverters and three mains side inverters, all paralleled on the dc link; a multi-winding transformer ( 3 primary, 1 secondary windings).

The following aspects will be analyzed (referring to a four winding transformer: FWT): coils disposition; transformer sizing criteria and constructional data; equivalent network and its parameter identification; Park equations of the inverter fed FWT; voltage and current harmonic analysis, currents THD, core and copper losses and efficiency for different inverter PWM command settings; comparison among analytical and FEM results.

\section{TRANSFORMER DESIGN CRITERIAAND MAIN DATA}

The disposition of the coils around each column could be based on various layouts: here, the concentric disposition will be considered, that is the most popular one, with classical equations for the analytical parameter estimation.

Fig. 2 shows the main FWT sizes: the LV primary windings $(1,2,3)$ are close to the column, while the MV secondary winding $(0)$ is external.

The sizing criteria, to which the design is inspired, are:

- the ratio $\mathrm{H} / \mathrm{F}$ should be low, in order to ensure high leakage inductances, so limiting the current ripples, due to inverters;

- the inverter switching frequency should be high enough to limit the current ripple and the FWT and inverter losses;

- the inter-coil distances should by higher than the minimum insulation distances, in order to provide high leakage paths; - of course, wide leakage paths imply increased radial sizes, copper mass and losses, (even if these drawbacks are compensated by absence or reduction of the output filters);

- chosen rated power and voltages, the rated currents are known: the copper losses can be limited by ensuring low 
resistance values, thus a low $\mathrm{N}^{\circ}$ of turns: this implies a high core cross section and a high turn EMF;

- conversely, a low $\mathrm{N}^{\circ}$ of turns implies low inductances and high core cross section, mass and losses;

- in order to limit the skin effect in the coil conductors, the conductor cross section must be suitably subdivided, with complete transposition of the elementary plates.

The application of all these criteria leads to define the rated and constructional data: they are resumed in Table I and will be considered during the following analysis.

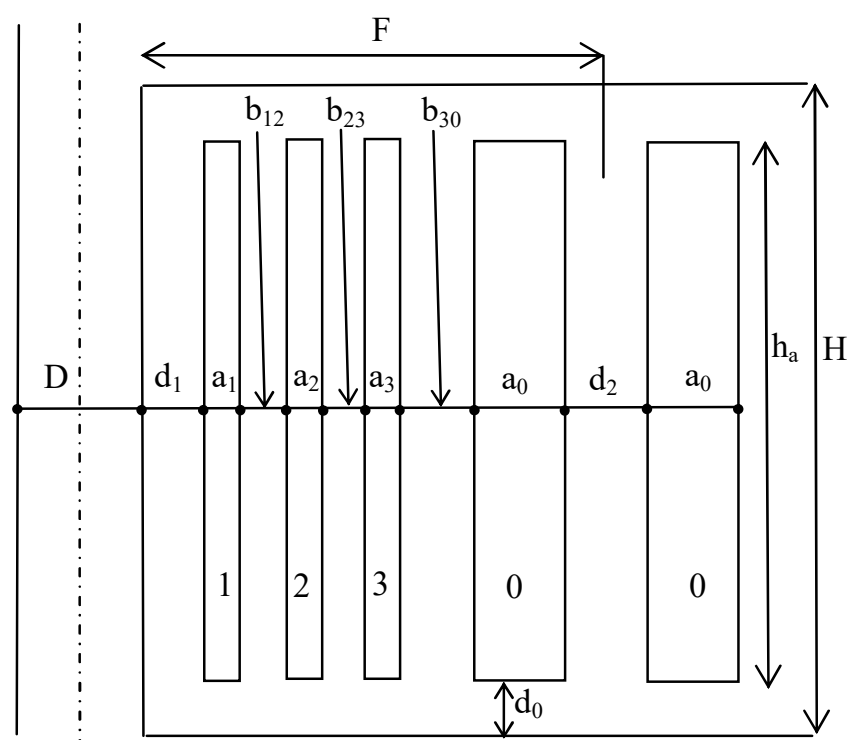

Fig. 2. Drawing in section of one core column of the four-winding transformer, with primary $\operatorname{LV}(1,2,3)$ coils and secondary MV coil (0), in case of concentric coil disposition; the main sizes involved in the transformer design are shown, with coil sizes and distances.

TABLE I

FOUR WINDING TRANSFORMER MAIN RATED AND CONSTRUCTIONAL DATA (SIZES IN [mm])

Rated voltages; frequency: $\quad \mathrm{V}_{\mathrm{LV}}=0.69 \mathrm{kV} ; \mathrm{V}_{\mathrm{HV}}=20 \mathrm{kV} ; \mathrm{f}_{\mathrm{n}}=50 \mathrm{~Hz}$ Rated active powers; PF: $\quad \mathrm{P}_{1}=\mathrm{P}_{2}=\mathrm{P}_{3}=1 \mathrm{MW} ; \mathrm{P}_{0}=3 \mathrm{MW} ; \mathrm{PF}=0.9$ Rated loadings, turn EMF: $\mathrm{B}=1.7 \mathrm{~T} ; \mathrm{S}=3 \mathrm{~A} / \mathrm{mm}^{2} ; \mathrm{E}_{\text {turn }}=40 \mathrm{~V}_{\mathrm{rms}}$ Connection; $\mathrm{LV}, \mathrm{HV} \mathrm{N}^{\circ}$ of turns: $\quad \mathrm{Yy} ; \quad \mathrm{N}_{\mathrm{LV}}=10, \quad \mathrm{~N}_{\mathrm{HV}}=290$

Axial and radial distances: $\mathrm{d}_{0}=40 \mathrm{~d}_{1}=23 \mathrm{~b}_{12}=\mathrm{b}_{23}=86 \mathrm{~b}_{30}=83.5 \mathrm{~d}_{2}=26 \mathrm{~h}_{\mathrm{a}}=330$ Column D, coils radial width: $\mathrm{D}=398.5 ; \mathrm{a}_{1}=\mathrm{a}_{2}=\mathrm{a}_{3}=15.2 ; \mathrm{a}_{0}=57.1$

LV coil data: helix disposition; $\mathrm{N}_{\mathrm{pp}}=2$ parallel paths; $\mathrm{N}_{\mathrm{pc}}$ plates/conductor, in 2 superposed layers: $\mathrm{N}_{\mathrm{pcLV}}=10+10$; plate size: $7.10 \times 1.12$

HV coil data: disk disposition, with $\mathrm{N}_{\mathrm{D}}=32$ disks; conductor consisting of $\mathrm{N}_{\mathrm{pcHV}}=3$ plates/conductor; plate size: $6.30 \times 1.70$

Lamin.; column $\mathrm{N}^{\circ}$ of steps; Fe, Cu masses [kg]: $\mathrm{M}-5 / 125 ; 8 ; 5538,796$

\section{TRANSFORMER MODEL AND PARAMETER IDENTIFICATION}

It is well known that the single-phase equivalent network of an $\mathrm{N}$ winding transformer can be identified by considering $\mathrm{N} \cdot(\mathrm{N}-1) / 2$ independent binary short circuit tests; thus, for a FWT, 6 short circuit tests are needed, corresponding to 6 short circuit impedances $\left(\bar{Z}_{12}, \bar{Z}_{13}, \bar{Z}_{10}, \bar{Z}_{23}, \bar{Z}_{20}, \bar{Z}_{30}\right)$. A classical equivalent network of the FWT is the Starr network [12], shown in fig. 3: its topology, here adopted, exhibits four external series impedances connected to the terminals $\left(\bar{Z}_{\mathrm{a}}, \bar{Z}_{\mathrm{b}}, \overline{\mathrm{Z}}_{\mathrm{c}}, \overline{\mathrm{Z}}_{\mathrm{d}}\right)$, and other two independent impedances $\left(\bar{Z}_{\mathrm{e}}, \bar{Z}_{\mathrm{f}}\right)$, doubled on the opposite sides of an internal quadrilateral loop.

The expressions of the 6 equivalent branch parameters of fig. 3 are reported in the Appendix, starting from the binary short circuit impedances.

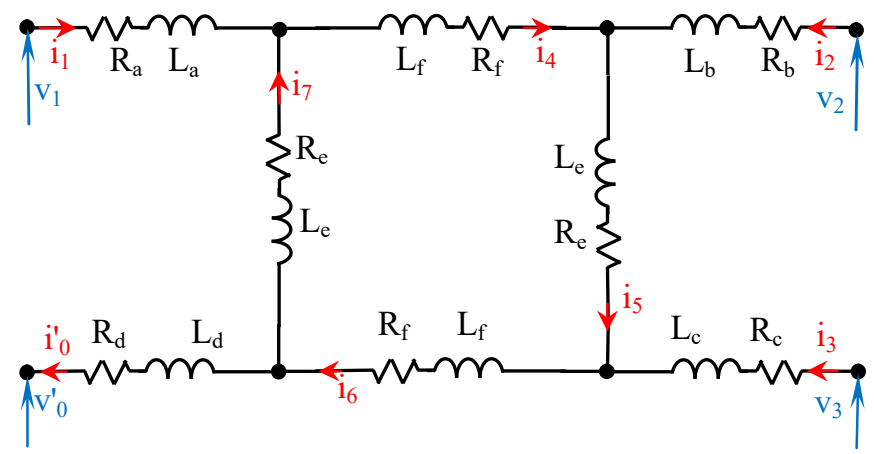

Fig. 3. Equivalent single-phase network of a four winding transformer, according to Starr [12]: the network includes 6 independent resistances and leakage inductances, all referred to the primary LV side (lower terminals are omitted and the derived magnetizing branch is neglected).

As concerns the binary short circuit parameters, based on the sizes of fig. 2 and Table I, the following analytical expression can be adopted for the ij binary inductance:

$$
\mathrm{L}_{\mathrm{ij}}=\mathrm{k}_{\mathrm{L}} \cdot \mathrm{p}_{\mathrm{ij}} \cdot \mathrm{c}_{\mathrm{ij}} \cdot \mathrm{K}_{\mathrm{Rij}} \quad, \quad \mathrm{ij}=12,13,10,23,20,30
$$

with $\mathrm{k}_{\mathrm{L}}$ common factor, $\mathrm{p}_{\mathrm{ij}}$ average perimeter, $\mathrm{c}_{\mathrm{ij}}$ distance between the electromagnetic centers, $\mathrm{K}_{\mathrm{Rij}}=\mathrm{K}_{\mathrm{R}}\left(\sigma_{\mathrm{ij}}\right)$ Rogoski factor (modeling fringing): in the Appendix their expressions.

The ohmic resistances of the four windings are given by:

$$
\begin{aligned}
& \mathrm{R}_{\mathrm{w} \Omega}=\frac{\rho_{\mathrm{cu}} \cdot \mathrm{N}_{\mathrm{LV}} \cdot \mathrm{p}_{\mathrm{w}}}{\mathrm{N}_{\mathrm{pp}} \cdot \mathrm{N}_{\mathrm{pcLV}} \cdot \mathrm{A}_{\mathrm{pLV}}} \quad \mathrm{w}=1,2,3 \\
& \mathrm{R}_{0 \Omega}^{\prime}=\frac{\rho_{\mathrm{cu}} \cdot \mathrm{N}_{\mathrm{HV}} \cdot \mathrm{p}_{0}}{\mathrm{~N}_{\mathrm{pcHV}} \cdot \mathrm{A}_{\mathrm{pHV}}} \cdot\left(\mathrm{N}_{\mathrm{LV}} / \mathrm{N}_{\mathrm{HV}}\right)^{2},
\end{aligned}
$$

with: $\rho_{\mathrm{cu}}=0.021 \mu \Omega \mathrm{m} ; \mathrm{N}_{\mathrm{pp}}=2: \mathrm{N}^{\circ}$ of LV parallel paths; $\mathrm{N}_{\mathrm{pcLV}}$ $=10+10: \mathrm{N}^{\circ}$ of transposed plates in each LV path conductor; $\mathrm{N}_{\mathrm{pcHV}}=3: \mathrm{N}^{\circ}$ of transposed plates in the HV conductor; $\mathrm{A}_{\mathrm{pLV}}$, $\mathrm{A}_{\mathrm{pHV}}$ standard plate cross sections (see Table I); the average coil perimeter formulas for $\mathrm{p}_{1}, \mathrm{p}_{2}, \mathrm{p}_{3}, \mathrm{p}_{0}$, are in Appendix.

As known, during binary short circuit tests, additional copper losses occur, due to skin effect, not only in the coils interested by currents at the fed and short-circuited terminals, but also in the internal open coils, in which just eddy currents occur, due to their immersion in the ac leakage field.

These losses are modeled by some well-known additional loss coefficients $k_{a}$, resumed in the Appendix: here just the binary short circuit resistances are given (referred to LV):

$$
\begin{aligned}
& \mathrm{R}_{12}=\mathrm{k}_{\mathrm{a} 1} \cdot \mathrm{R}_{1 \Omega}+\mathrm{k}_{\mathrm{a} 2} \cdot \mathrm{R}_{2 \Omega} \\
& \mathrm{R}_{13}=\mathrm{k}_{\mathrm{a} 1} \cdot \mathrm{R}_{1 \Omega}+\mathrm{k}_{\mathrm{a} 2 \mathrm{p}} \cdot \mathrm{R}_{2 \Omega}+\mathrm{k}_{\mathrm{a} 3} \cdot \mathrm{R}_{3 \Omega} \\
& \mathrm{R}_{10}=\mathrm{k}_{\mathrm{a} 1} \cdot \mathrm{R}_{1 \Omega}+\mathrm{k}_{\mathrm{a} 2 \mathrm{p}} \cdot \mathrm{R}_{2 \Omega}+\mathrm{k}_{\mathrm{a} 3 \mathrm{p}} \cdot \mathrm{R}_{3 \Omega}+\mathrm{k}_{\mathrm{a} 0} \cdot \mathrm{R}_{0 \Omega}^{\prime} \\
& \mathrm{R}_{23}=\mathrm{k}_{\mathrm{a} 2} \cdot \mathrm{R}_{2 \Omega}+\mathrm{k}_{\mathrm{a} 3} \cdot \mathrm{R}_{3 \Omega} \\
& \mathrm{R}_{20}=\mathrm{k}_{\mathrm{a} 2} \cdot \mathrm{R}_{2 \Omega}+\mathrm{k}_{\mathrm{a} 3 \mathrm{p}} \cdot \mathrm{R}_{3 \Omega}+\mathrm{k}_{\mathrm{a} 0} \cdot \mathrm{R}_{0 \Omega}^{\prime} \\
& \mathrm{R}_{30}=\mathrm{k}_{\mathrm{a} 3} \cdot \mathrm{R}_{3 \Omega}+\mathrm{k}_{\mathrm{a} 0} \cdot \mathrm{R}_{0 \Omega}^{\prime}
\end{aligned}
$$

Considering that the additional loss coefficients depend on frequency, the same occurs for the binary short circuit 
resistances and for the Starr equivalent network resistances.

At the fundamental inverter frequency $\mathrm{f}_{1}$, equal to the mains frequency, using (A1)-(A7) we obtain the equivalent Starr inductive and resistive parameters: for the fig. 1 layout, with the Table I data, at $\mathrm{f}_{1}=50 \mathrm{~Hz}$ the data of Table II follow.

\section{TABLE II}

EQUIVALENT STARR NETWORK PARAMETERS FROM BINARY SHORT-CIRCUIT IMPEDANCES AT MAINS FREQUENCY $(50 \mathrm{~Hz})$

\begin{tabular}{c|c|c|c|c|c}
\hline $\mathrm{L}_{\mathrm{a}}[\mu \mathrm{H}]$ & $\mathrm{L}_{\mathrm{b}}[\mu \mathrm{H}]$ & $\mathrm{L}_{\mathrm{c}}[\mu \mathrm{H}]$ & $\mathrm{L}_{\mathrm{d}}[\mu \mathrm{H}]$ & $\mathrm{L}_{\mathrm{e}}[\mu \mathrm{H}]$ & $\mathrm{L}_{\mathrm{f}}[\mu \mathrm{H}]$ \\
\hline 10.09 & -9.57 & -4.31 & 46.90 & 123.23 & 58.59 \\
\hline $\mathrm{R}_{\mathrm{a}}[\mu \Omega]$ & $\mathrm{R}_{\mathrm{b}}[\mu \Omega]$ & $\mathrm{R}_{\mathrm{c}}[\mu \Omega]$ & $\mathrm{R}_{\mathrm{d}}[\mu \Omega]$ & $\mathrm{R}_{\mathrm{e}}[\mu \Omega]$ & $\mathrm{R}_{\mathrm{f}}[\mu \Omega]$ \\
\hline 0.9826 & 1.4079 & 1.8388 & 0.8274 & 0.0187 & 0.0036 \\
\hline
\end{tabular}

It should be noted that some parameters are negative, but this is not an oddity: in fact, as known, the network is equivalent as a global system. Nothing can be said on single elements, which cannot be associated to specific internal machine parts.

In sinusoidal operation these parameters would be suited to analyze the operating conditions of the FWT.

In principle, the presence of the inverters makes incorrect system analysis in time domain, because the resistances are different at the various inverter harmonic voltages.

The correct approach should be: inverter voltage waveforms Fourier decomposition; calculation of harmonic impedances; evaluation of the network harmonic currents and of their THD; copper and core harmonic losses estimation; efficiency calculation. All these items can be estimated harmonic by harmonic. To gain the time domain current waveforms, the harmonic instantaneous currents should be added.

The calculation of the parameters as a function of the harmonic order leads to the following results:

- the leakage inductances evaluated from the second of (A7), starting from the binary short circuit impedances and using (A1)-(A6), result not dependent on frequency, as expected and physically reasonable (because the changing skin effect in the plates has a minor effect on leakage field energy);

- on the contrary, the resistance values are frequency dependent, as shown in Table III.

TABLE III

EQuivalent StARr NETWORK RESISTANCES, FOR THE FWT OF Fig. 2 AND TABLE I, AS A FUNCTION OF THE HARMONIC ORDER (WITH $f_{1}=50 \mathrm{~Hz}$ )

\begin{tabular}{|c|c|c|c|c|c|c|}
\hline $\mathrm{R}_{\mathrm{h}}$ & $\begin{array}{c}\mathrm{R}_{\mathrm{ah}} \\
{[\mathrm{m} \Omega]}\end{array}$ & $\begin{array}{c}\mathrm{R}_{\mathrm{bh}} \\
{[\mathrm{m} \Omega]}\end{array}$ & $\begin{array}{c}\mathrm{R}_{\mathrm{ch}} \\
{[\mathrm{m} \Omega]}\end{array}$ & $\begin{array}{c}\mathrm{R}_{\mathrm{dh}} \\
{[\mathrm{m} \Omega]}\end{array}$ & $\begin{array}{c}\mathrm{R}_{\mathrm{eh}} \\
{[\mathrm{m} \Omega]}\end{array}$ & $\begin{array}{c}\mathrm{R}_{\mathrm{fh}} \\
{[\mathrm{m} \Omega]}\end{array}$ \\
\hline 0 & 0.980 & 1.411 & 1.842 & 0.809 & 0 & 0 \\
\hline 1 & 0.983 & 1.408 & 1.839 & 0.827 & 0.019 & 0.004 \\
\hline 10 & 1.278 & 1.122 & 1.520 & 2.680 & 1.865 & 0.358 \\
\hline 100 & 29.27 & -25.90 & -28.64 & 172.2 & 176.6 & 33.91 \\
\hline 1000 & 481.4 & -460.9 & -514.0 & 2062 & 2995 & 574.7 \\
\hline
\end{tabular}

The following remarks can be made:

$-\mathrm{R}_{\mathrm{a} 0}, \mathrm{R}_{\mathrm{b} 0}, \mathrm{R}_{\mathrm{c} 0}, \mathrm{R}_{\mathrm{d} 0}$ are the dc coil resistances $\mathrm{R}_{\mathrm{a} \Omega}, \mathrm{R}_{\mathrm{b} \Omega}, \mathrm{R}_{\mathrm{c} \Omega}$, $R_{d \Omega}$, while the internal loop resistances $R_{e 0}$ and $R_{f 0}$ are zero; - the resistances at fundamental frequency are close to the dc values: $\mathrm{R}_{\mathrm{a} 1}, \mathrm{R}_{\mathrm{d} 1}$ are slightly higher than $\mathrm{R}_{\mathrm{a} \Omega}, \mathrm{R}_{\mathrm{d} \Omega}$; the opposite occurs for $\mathrm{R}_{b 1}, \mathrm{R}_{\mathrm{cl}}$ with respect to $\mathrm{R}_{\mathrm{b} \Omega}, \mathrm{R}_{\mathrm{c} \Omega}$;

- the increasing trend of $R_{a h}$ and $R_{d h}$ and the decreasing trend of $R_{b h}$ and $R_{c h}$ is also confirmed for higher order harmonics, till a change of sign of $R_{b h}$ and $R_{c h}$ : this behavior is similar to that of negative inductances; also here, the equivalent circuit single resistance does not have a physical meaning: the only valid model refers to the global network.

Considering the impedance amplitude and characteristic angle as a function of the harmonic order, even taking into account the resistance frequency dependence, the branch reactance is always prevailing with respect to the resistance. If we define:

$$
\begin{gathered}
\rho_{\mathrm{Zm}}(\mathrm{h})=\left|\mathrm{Z}_{\mathrm{mh}} /\left(\mathrm{h} \cdot \omega_{1} \cdot \mathrm{L}_{\mathrm{m}}\right)\right|, \quad \mathrm{m}=\mathrm{a}, \mathrm{b}, \mathrm{c}, \mathrm{d}, \mathrm{e}, \mathrm{f} \\
\varphi_{\mathrm{m}}^{\mathrm{o}}(\mathrm{h})=(180 / \pi) \cdot \operatorname{atan}\left[\left|\left(\mathrm{h} \cdot \omega_{1} \cdot \mathrm{L}_{\mathrm{m}}\right) / \mathrm{R}_{\mathrm{mh}}\right|\right],
\end{gathered}
$$

the trend is shown in the diagrams of fig. 4; in fact:

- the impedance amplitude of the branches a, b, d, e, f are very close to the corresponding pure reactances;

- the characteristic angles of the branches a, b, d, e, f are not too far from $90^{\circ}$;

- the only impedance with an appreciable deviation with respect to $\omega \cdot \mathrm{L}$ trend is $\bar{Z}_{c}$, both in amplitude and in angle: however, this has a limited effect on the network behavior.
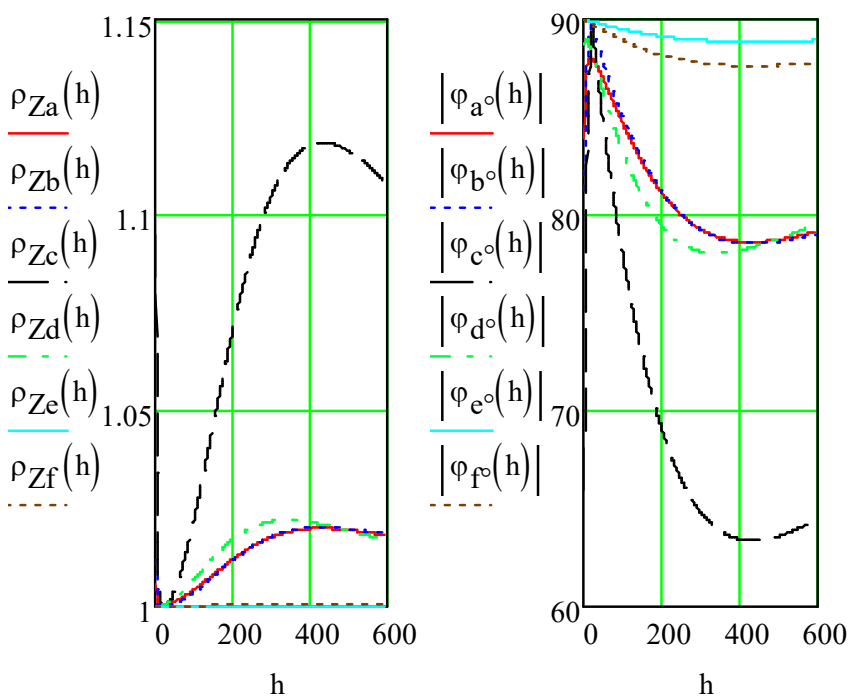

Fig. 4. Impedance ratio (10) and characteristic angle (11) of the Starr equivalent branches, as a function of the harmonic order.

These considerations reasonably justify the adoption of a time domain approximated approach to the system analysis, based on the state equations, in which the branch resistances have the values calculated at the fundamental harmonics.

In order to identify the order of the dynamic network of fig. 2, it is useful to observe that the inductive currents are eight, but not independent among them, due to the following algebraic independent links:

$$
\begin{aligned}
& \mathrm{i}_{0}^{\prime}=\mathrm{i}_{1}+\mathrm{i}_{2}+\mathrm{i}_{3} \\
& \mathrm{i}_{5}=\mathrm{i}_{2}+\mathrm{i}_{4} \\
& \mathrm{i}_{6}=\mathrm{i}_{2}+\mathrm{i}_{3}+\mathrm{i}_{4} \\
& \mathrm{i}_{7}=\mathrm{i}_{4}-\mathrm{i}_{1} .
\end{aligned}
$$

For now referring to the single phase system of fig. 2, defined the vector of the state variable currents $\mathbf{i}$ :

$$
\mathbf{i}=\left[\begin{array}{llll}
\mathrm{i}_{1} & \mathrm{i}_{2} & \mathrm{i}_{3} & \mathrm{i}_{4}
\end{array}\right]^{\mathrm{T}}
$$

and the vector of the voltage sources $\mathbf{v}_{\mathbf{i} 0}$ : 


$$
\mathbf{v}_{\mathbf{i} 0}=\left[\begin{array}{llll}
\left(v_{1}-v_{0}^{\prime}\right) & \left(v_{2}-v_{0}^{\prime}\right) & \left(v_{3}-v_{0}^{\prime}\right) & 0
\end{array}\right]^{T},
$$

the system of state equations in matrix form is given by:

$$
\mathbf{L}_{\mathbf{S}} \cdot \mathrm{d} \mathbf{i} / \mathrm{dt}=-\mathbf{R}_{\mathbf{S}} \cdot \mathbf{i}+\mathbf{v}_{\mathrm{i} 0},
$$

where the inductance $\mathbf{L}_{\mathbf{S}}$ and resistance $\mathbf{R}_{\mathbf{S}}$ matrices equal:

$$
\begin{array}{r}
\mathrm{L}_{\mathrm{S}}:=\left[\begin{array}{cccc}
\left(\mathrm{L}_{\mathrm{a}}+\mathrm{L}_{\mathrm{e}}+\mathrm{L}_{\mathrm{d}}\right) & \mathrm{L}_{\mathrm{d}} & \mathrm{L}_{\mathrm{d}} & \left(-\mathrm{L}_{\mathrm{e}}\right) \\
\mathrm{L}_{\mathrm{d}} & \left(\mathrm{L}_{\mathrm{b}}+\mathrm{L}_{\mathrm{e}}+\mathrm{L}_{\mathrm{f}}+\mathrm{L}_{\mathrm{d}}\right) & \left(\mathrm{L}_{\mathrm{f}}+\mathrm{L}_{\mathrm{d}}\right) & \left(\mathrm{L}_{\mathrm{e}}+\mathrm{L}_{\mathrm{f}}\right) \\
\mathrm{L}_{\mathrm{d}} & \left(\mathrm{L}_{\mathrm{f}}+\mathrm{L}_{\mathrm{d}}\right) & \left(\mathrm{L}_{\mathrm{c}}+\mathrm{L}_{\mathrm{f}}+\mathrm{L}_{\mathrm{d}}\right) & \mathrm{L}_{\mathrm{f}} \\
\left(-\mathrm{L}_{\mathrm{e}}\right) & \left(\mathrm{L}_{\mathrm{e}}+\mathrm{L}_{\mathrm{f}}\right) & \mathrm{L}_{\mathrm{f}} & 2 \cdot\left(\mathrm{L}_{\mathrm{e}}+\mathrm{L}_{\mathrm{f}}\right)
\end{array}\right] \\
\mathrm{R}_{\mathrm{S}}:=\left[\begin{array}{cccc}
\left(\mathrm{R}_{\mathrm{a}}+\mathrm{R}_{\mathrm{e}}+\mathrm{R}_{\mathrm{d}}\right) & \mathrm{R}_{\mathrm{d}} & \mathrm{R}_{\mathrm{d}} & \left(-\mathrm{R}_{\mathrm{e}}\right) \\
\mathrm{R}_{\mathrm{d}} & \left(\mathrm{R}_{\mathrm{b}}+\mathrm{R}_{\mathrm{e}}+\mathrm{R}_{\mathrm{f}}+\mathrm{R}_{\mathrm{d}}\right) & \left(\mathrm{R}_{\mathrm{f}}+\mathrm{R}_{\mathrm{d}}\right) & \left(\mathrm{R}_{\mathrm{e}}+\mathrm{R}_{\mathrm{f}}\right) \\
\mathrm{R}_{\mathrm{d}} & \left(\mathrm{R}_{\mathrm{f}}+\mathrm{R}_{\mathrm{d}}\right) & \left(\mathrm{R}_{\mathrm{c}}+\mathrm{R}_{\mathrm{f}}+\mathrm{R}_{\mathrm{d}}\right) & \mathrm{R}_{\mathrm{f}} \\
\left(-\mathrm{R}_{\mathrm{e}}\right) & \left(\mathrm{R}_{\mathrm{e}}+\mathrm{R}_{\mathrm{f}}\right) & \mathrm{R}_{\mathrm{f}} & 2 \cdot\left(\mathrm{R}_{\mathrm{e}}+\mathrm{R}_{\mathrm{f}}\right)
\end{array}\right]
\end{array}
$$

The optimal operating condition for the FWT should imply a balanced sharing of the primary currents, which should have the same amplitude and the same phase.

In terms of fundamental currents, this means:

$$
\overline{\mathrm{I}}_{1}=\overline{\mathrm{I}}_{2}=\overline{\mathrm{I}}_{3}=\mathrm{I}_{\mathrm{pn}} \cdot \mathrm{e}^{-\mathrm{j} \cdot \varphi} \quad, \quad \overline{\mathrm{I}}_{0}^{\prime}=3 \cdot \overline{\mathrm{I}}_{1}
$$

with $\mathrm{I}_{\mathrm{pn}}$ rated primary current and $\varphi=\operatorname{acos}(\mathrm{PF}), \mathrm{PF}=$ desired power factor (here $\mathrm{PF}=0.9$ is assumed); as concerns $\overline{\mathrm{I}}_{4}$, it can be expressed as a function of $\overline{\mathrm{I}}_{1}, \overline{\mathrm{I}}_{2}, \overline{\mathrm{I}}_{3}$, by writing the Kirchhoff voltage law along the internal loop:

$$
\overline{\mathrm{I}}_{4}=\frac{1}{2} \cdot\left[\overline{\mathrm{Z}}_{\mathrm{e}} \cdot \overline{\mathrm{I}}_{1}-\left(\overline{\mathrm{Z}}_{\mathrm{e}}+\overline{\mathrm{Z}}_{\mathrm{f}}\right) \cdot \overline{\mathrm{I}}_{2}-\overline{\mathrm{Z}}_{\mathrm{f}} \cdot \overline{\mathrm{I}}_{3}\right] /\left(\overline{\mathrm{Z}}_{\mathrm{e}}+\overline{\mathrm{Z}}_{\mathrm{f}}\right)
$$

By considering the fundamental components, (18) is transformed in a phasor matrix equation:

$$
\overline{\mathbf{V}}_{\mathbf{i}}=\overline{\mathbf{V}}_{\mathbf{0}}+\overline{\mathbf{Z}}_{\mathbf{S}} \cdot \overline{\mathbf{I}}
$$

where

$$
\begin{aligned}
& \overline{\mathbf{Z}}_{\mathbf{S}}=\mathbf{R}_{\mathbf{S}}+\mathrm{j} \cdot \omega_{1} \cdot \mathbf{L}_{\mathbf{S}}, \\
& \overline{\mathbf{V}}_{\mathbf{0}}^{\prime}=\left[\begin{array}{llll}
\mathrm{V}_{0}^{\prime} & \mathrm{V}_{0}^{\prime} & \mathrm{V}_{0}^{\prime} & 0
\end{array}\right]^{\mathrm{T}},
\end{aligned}
$$

with $\mathrm{V}_{0}^{\prime}=\left(\mathrm{V}_{\mathrm{HV}} / \sqrt{ } 3\right) \cdot \mathrm{N}_{\mathrm{LV}} / \mathrm{N}_{\mathrm{HV}}$. By putting (21), (22) in (23), calculating $\overline{\mathbf{V}}_{\mathbf{i}}$ gives the inverter fundamental voltages $\overline{\mathrm{V}}_{1}, \overline{\mathrm{V}}_{2}, \overline{\mathrm{V}}_{3}$.

Of course, the inverter control strategy should follow a current control using (21); however, (23) is useful to check if the inverter modulation ratios $\mathrm{m}_{\mathrm{a} 1}, \mathrm{~m}_{\mathrm{a} 2}, \mathrm{~m}_{\mathrm{a} 3}$ are suited:

$$
\mathrm{m}_{\mathrm{ai}}=2 \cdot \sqrt{2} \cdot \mathrm{V}_{\mathrm{i}} / \mathrm{V}_{\mathrm{dc}} \quad, \quad \mathrm{i}=1,2,3
$$

(here $\mathrm{V}_{\mathrm{dc}}=1.4 \mathrm{kV}$ and in loaded operation $\mathrm{m}_{\mathrm{ai}}$ values are about 0.9). Moreover, the phases of $\overline{\mathrm{V}}_{1}, \overline{\mathrm{V}}_{2}, \overline{\mathrm{V}}_{3}$ are also the phases of the inverter control signals.

By considering that FWT, inverters and mains are 3-phase components, (18) remains valid, provided that the voltage and current vectors become vectors of Park quantities:

$$
\begin{gathered}
\mathbf{i}_{\mathrm{P}}=\left[\begin{array}{llll}
\mathrm{i}_{1 \mathrm{P}} & \mathrm{i}_{2 \mathrm{P}} & \mathrm{i}_{3 \mathrm{P}} & \mathrm{i}_{4 \mathrm{P}}
\end{array}\right]^{\mathrm{T}} \\
\mathbf{v}_{\mathrm{i} 0 \mathrm{P}}=\left[\begin{array}{llll}
\left(\mathrm{v}_{1 \mathrm{P}}-\mathrm{v}^{\prime}{ }_{0 \mathrm{P}}\right) & \left(\mathrm{v}_{2 \mathrm{P}}-\mathrm{v}^{\prime}{ }_{0 \mathrm{P}}\right) & \left(\mathrm{v}_{3 \mathrm{P}}-\mathrm{v}^{\prime}{ }_{0 \mathrm{P}}\right) & 0
\end{array}\right]^{\mathrm{T}}
\end{gathered}
$$

Thus, (18) in normal form becomes:

$$
\frac{\mathrm{d} \mathbf{i}_{\mathrm{P}}}{\mathrm{dt}}=-\mathbf{L}_{\mathbf{S}}^{-1} \cdot \mathbf{R}_{\mathrm{S}} \cdot \mathbf{i}_{\mathrm{P}}+\mathbf{L}_{\mathbf{S}}^{-1} \cdot \mathbf{v}_{\mathrm{i} 0 \mathrm{P}}
$$

The integration of (29) should be extended until the steady state periodic operation is reached. Then, also using (12)(15), the current harmonics $\mathrm{I}_{1 \mathrm{~h}}, \mathrm{I}_{2 \mathrm{~h}}, \mathrm{I}_{3 \mathrm{~h}}, \mathrm{I}_{4 \mathrm{~h}}, \mathrm{I}_{0 \mathrm{~h}}^{\prime}, \mathrm{I}_{5 \mathrm{~h}}, \mathrm{I}_{6 \mathrm{~h}}, \mathrm{I}_{7 \mathrm{~h}}$ are estimated by FFT, so that the THD of the currents $i_{1}, i_{2}, i_{3}, i_{0}^{\prime}$ at the terminals can be calculated. Moreover, the global copper losses for each harmonic order $\mathrm{h}$ follow:

$$
\begin{gathered}
\mathrm{P}_{\text {cuh }}=3 \cdot \sum_{\mathrm{w}=0}^{7} \mathrm{R}_{\mathrm{wh}} \cdot \mathrm{I}_{\mathrm{wh}}^{2}, \\
\text { with } \mathrm{R}_{1 \mathrm{~h}}=\mathrm{R}_{\mathrm{ah}}, \quad \mathrm{R}_{2 \mathrm{~h}}=\mathrm{R}_{\mathrm{bh}}, \quad \mathrm{R}_{3 \mathrm{~h}}=\mathrm{R}_{\mathrm{ch}}, \mathrm{R}_{0 \mathrm{~h}}=\mathrm{R}_{\mathrm{dh}} \\
\mathrm{R}_{4 \mathrm{~h}}=\mathrm{R}_{\mathrm{fh}}, \quad \mathrm{R}_{5 \mathrm{~h}}=\mathrm{R}_{\mathrm{eh}}, \quad \mathrm{R}_{6 \mathrm{~h}}=\mathrm{R}_{\mathrm{fh}}, \quad \mathrm{R}_{7 \mathrm{~h}}=\mathrm{R}_{\mathrm{eh}} .
\end{gathered}
$$

Of course, the total copper losses are calculated as follows:

$$
\mathrm{P}_{\mathrm{cu}}=\sum_{\mathrm{h}=1}^{\infty} \mathrm{P}_{\mathrm{cuh}}
$$

To complete the losses analysis of the inverter fed FWT, it is necessary to estimate the core losses.

Here, the following assumptions are taken:

- the considered loss items are hysteresis and eddy losses;

- the core losses are evaluated in no-load conditions, under no-load voltage feeding due to inverters;

- due to zero voltage drops in no-load FWT operation, the inverter voltage waveforms to be generated are the same: so, just one inverter feeding can be considered.

If the core losses curves are known at two different frequencies (for example, typically 50 and $60 \mathrm{~Hz}$ ), the hysteresis and eddy current specific losses in sinusoidal operation (per unit mass, at variable frequency $\mathrm{f}$ and with variable flux density peak value B) can be separated and expressed as follows:

$$
\begin{aligned}
& p_{\text {fe.hy }}(B, f)=p_{\text {hy.ref }}(B) \cdot\left(f / f_{\text {ref }}\right) \\
& p_{\text {fe.ec }}(B, f)=C_{\text {ec }} \cdot\left(B / B_{\text {ref }}\right) \cdot\left(f / f_{\text {ref }}\right)^{2}
\end{aligned}
$$

where $C_{e c}$ is the specific eddy current loss at the reference values $B_{\text {ref }}$ and $f_{\text {ref }}$ and $p_{\text {hy.ref }}(B)$ is the curve of the specific hysteresis loss at reference frequency $f_{\text {ref }}$, as a function of $B$.

Considering the inverter voltage rms harmonic values $V_{\text {ih }}$, the corresponding spectrum peak components $B_{h}$ of the flux density waveform in the core equal:

$$
B_{h}=\left[\sqrt{2} /\left(\omega_{1} \cdot N_{L V} \cdot A_{f e}\right)\right] \cdot V_{i h} / h=k_{\text {core }} \cdot V_{i h} / h,
$$

where $\mathrm{A}_{\mathrm{fe}}$ is the net column core cross section.

By calculating the cos and sin inverter voltage harmonic components $\mathrm{V}_{\mathrm{iCh}}$ and $\mathrm{V}_{\mathrm{iSh}}$, the $\mathrm{B}$ components follow:

$$
\mathrm{B}_{\mathrm{Ch}}=\mathrm{k}_{\text {core }} \cdot \mathrm{V}_{\mathrm{iCh}} / \mathrm{h}, \quad \mathrm{B}_{\mathrm{Sh}}=\mathrm{k}_{\text {core }} \cdot \mathrm{V}_{\mathrm{iSh}} / \mathrm{h} .
$$

Thus, the flux density waveform can be obtained:

$$
\mathrm{b}(\mathrm{t})=\sum_{\mathrm{h}=1}^{\infty}\left(\mathrm{B}_{\mathrm{Ch}} \cdot \cos \left(\mathrm{h} \cdot \omega_{1} \cdot \mathrm{t}\right)+\mathrm{B}_{\mathrm{Sh}} \cdot \sin \left(\mathrm{h} \cdot \omega_{1} \cdot \mathrm{t}\right)\right) \text {, }
$$

that allows to evaluate the peak instantaneous value $\hat{B}$. Therefore, the specific hysteresis loss equals:

$$
p_{\text {fe.hy }}(\hat{B}, f)=p_{\text {hy.ref }}(\hat{B}) \cdot\left(f_{1} / f_{\text {ref }}\right) \text {. }
$$

In fact, in absence of minor hysteresis loops (or neglecting them), the hysteresis loss depends on the instantaneous peak value $\hat{B}$ only, regardless the $b(t)$ waveform, that affects the local speed along the hysteresis loop trajectory in the B-H 
plane. Thus, considering that $\hat{\mathrm{B}}$ should be quite close to the fundamental peak value $B_{1}$, the hysteresis loss in distorted operation is not too different with respect to the hysteresis loss in sinusoidal operation at $\mathrm{f}=\mathrm{f}_{1}$.

As concerns the eddy current losses, in principle it is possible to calculate the loss for each harmonic order by using (35), then adding the harmonic loss contributions. However, it should be noted that, for high order harmonics, the eddy currents have a reaction effect as they modify the flux density distribution in the lamination width, that is no longer uniform. This can be taken into account by a classical reduction factor, which depends on frequency as follows:

$$
\begin{gathered}
\mathrm{k}_{\mathrm{fe}}(\mathrm{f})=\frac{3}{\xi_{\mathrm{fe}}(\mathrm{f})} \cdot \frac{\sinh \left(\xi_{\mathrm{fe}}(\mathrm{f})\right)-\sin \left(\xi_{\mathrm{fe}}(\mathrm{f})\right)}{\cosh \left(\xi_{\mathrm{fe}}(\mathrm{f})\right)-\cos \left(\xi_{\mathrm{fe}}(\mathrm{f})\right)} \\
\xi_{\mathrm{fe}}(\mathrm{f})=\delta_{\mathrm{lam}} / \mathrm{p}_{\mathrm{d}}(\mathrm{f}), \quad \mathrm{p}_{\mathrm{d}}(\mathrm{f})=\sqrt{\rho_{\mathrm{fe}} /\left(\pi \cdot \mu_{\mathrm{fe}} \cdot \mathrm{f}\right)}
\end{gathered}
$$

where $\delta_{\text {lam }}$ is the lamination width, $\mathrm{p}_{\mathrm{d}}$ the penetration depth, and $\mu_{\mathrm{fe}}$ the lamination apparent permeability at $\hat{\mathrm{B}}$ (or at $\mathrm{B}_{1}$ ). $\mathrm{k}_{\mathrm{fe}}$ equals 1 at low industrial frequency and tends asymptotically to zero at high frequency values.

In conclusion, the specific eddy losses in distorted operation can be calculated as the fundamental frequency specific eddy losses times an additional loss coefficient $\mathrm{k}_{\mathrm{aec}}$, as follows:

$$
\begin{aligned}
& \mathrm{p}_{\text {fe.ec.dist }}=\mathrm{k}_{\mathrm{aec}} \cdot \mathrm{p}_{\text {fe.ec }}\left(\mathrm{B}_{1}, \mathrm{f}_{1}\right) \\
& \mathrm{k}_{\mathrm{aec}}=1+\sum_{\mathrm{h}=2}^{\infty} \mathrm{h}^{2} \cdot\left(\mathrm{B}_{\mathrm{h}} / \mathrm{B}_{1}\right)^{2} \cdot \mathrm{k}_{\mathrm{fe}}\left(\mathrm{h} \cdot \mathrm{f}_{1}\right)
\end{aligned}
$$

Besides, in order to take into account also some technological effects (non-uniform flux density distribution near the core joints, lamination burrs, mechanical stress...), another additional loss factor $\mathrm{k}_{\mathrm{a} \text {.tec }}$ should be considered: its value depends on the core manufacture process and on the lamination quality; here $\mathrm{k}_{\mathrm{a} . \mathrm{tec}}=1.15$ is assumed.

Finally, the total core losses equal:

$$
\mathrm{P}_{\mathrm{fe}}=\mathrm{k}_{\mathrm{a} . \mathrm{tec}} \cdot\left(\mathrm{p}_{\mathrm{fe} . \mathrm{hy}}\left(\hat{\mathrm{B}}, \mathrm{f}_{1}\right)+\mathrm{k}_{\mathrm{aec}} \cdot \mathrm{p}_{\text {fe.ec }}\left(\mathrm{B}_{1}, \mathrm{f}_{1}\right)\right) \cdot \mathrm{M}_{\mathrm{fe}}
$$

On average, the core losses in distorted operation results 1.21.3 times the core losses in sinusoidal operation for $B_{1}$ and $f_{1}$.

\section{TRANSFORMER PERFORMANCES}

Here some results concerning the FWT will be shown and discussed, under different inverter feeding conditions, always considering rated power: two frequency ratios will be considered $\left(\mathrm{m}_{\mathrm{f}}=99\right.$ or 33 , corresponding to $\mathrm{f}_{\text {carrier }}=4.95$ or $1.65 \mathrm{kHz}$ respectively), with carrier signals displaced by $1 / 3$ of the carrier period $\mathrm{T}_{\text {carrier }}$, or in phase among them.

The following remarks can be made:

- the primary current balance is acceptable, with almost equal and in phase currents;

- all the total copper losses for each harmonic order are positive, as expected;

- the case A leads to the minimum secondary current THD $(1.80 \%)$, thanks to the high carrier frequency and the shifted carrier signals;

- however, the primary current ripples of case A are wide, with large THD and $\mathrm{Cu}$ losses: in fact, the shift among carrier signals implies instantaneous voltage differences among couples of primary terminals, generating wide currents for harmonic order close to $\mathrm{m}_{\mathrm{f}}$ and multiples;

- the described behavior is confirmed by the case $\mathrm{B}$ results, that show a higher secondary current THD (2.82\%), but lower primary current harmonics and THD and lower $\mathrm{Cu}$ losses; the core losses are the same, depending on $\mathrm{m}_{\mathrm{f}}$ only;

A. Frequency ratio $\mathrm{m}_{\mathrm{f}}=99$; displaced carrier signals.

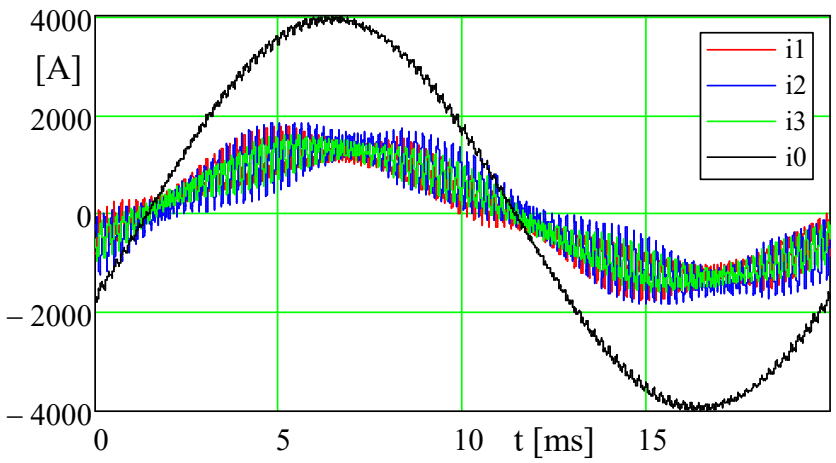

Fig. 5. Waveforms of the primary currents and of the secondary current (referred to the primary): carrier signals displaced by $1 / 3$ of the carrier

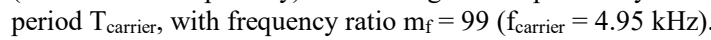

TABLE IV

CurRent Fundamental, MaIn HaRmonics AND THD; TOTAL Cu AND FE LOSSES; EFFICIENCY $\left(\mathrm{m}_{\mathrm{f}}=99\right.$, CARRIER SigNALS DiSPLACED BY $\left.1 / 3 \mathrm{~T}_{\text {carrier }}\right)$.

\begin{tabular}{c|c|c|c|c|}
\hline Current & $\mathrm{i}_{1}$ & $\mathrm{i}_{2}$ & $\mathrm{i}_{3}$ & $\mathrm{i}_{0}{ }^{\prime}$ \\
\hline $\mathrm{I}_{\text {fund }}\left[\mathrm{A}_{\mathrm{rms}}\right]$ & 898 & 970 & 922 & 2785 \\
\hline $\mathrm{I}_{(\mathrm{mf}-2)} / \mathrm{I}_{\text {fund }}[\%]$ & 16.65 & 20.67 & 13.95 & 1.15 \\
\hline $\mathrm{I}_{(\mathrm{mf}+2)} / \mathrm{I}_{\text {fund }}[\%]$ & 16.03 & 19.03 & 12.89 & 1.03 \\
\hline $\mathrm{I}_{(2 \mathrm{mf}-1)} / \mathrm{I}_{\text {fund }}[\%]$ & 7.62 & 9.22 & 6.67 & 0.56 \\
\hline $\mathrm{I}_{(2 \mathrm{mf}+1)} / \mathrm{I}_{\text {fund }}[\%]$ & 7.51 & 9.33 & 6.73 & 0.57 \\
\hline $\mathrm{THD} \mathrm{I}_{\mathrm{I}}[\%]$ & 25.5 & 31.1 & 21.3 & 1.80 \\
\hline $\mathrm{Cu}$ losses $[\mathrm{kW}]=46.6$ & \multicolumn{2}{|c|}{ Fe losses $[\mathrm{kW}]=8.52$} & \multicolumn{2}{c|}{ Efficiency $=98.20 \%$} \\
\hline
\end{tabular}

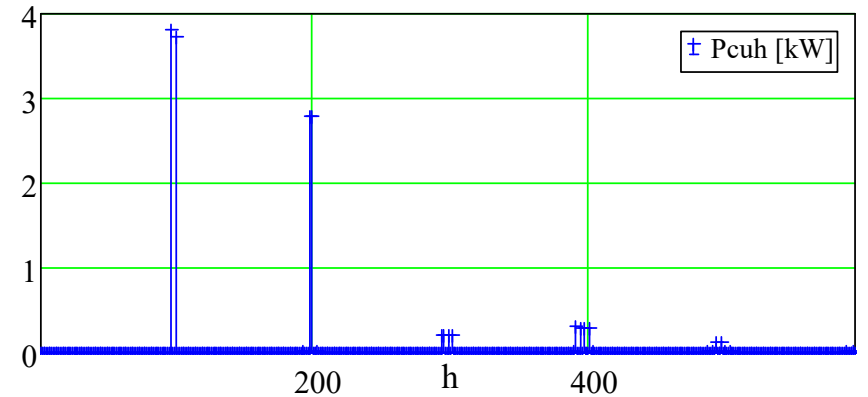

Fig. 6. Total copper losses for harmonic orders $>1$ : carrier signals displaced

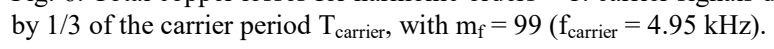

\section{B. Frequency ratio $\mathrm{m}_{\mathrm{f}}=99$; in phase carrier signals.}

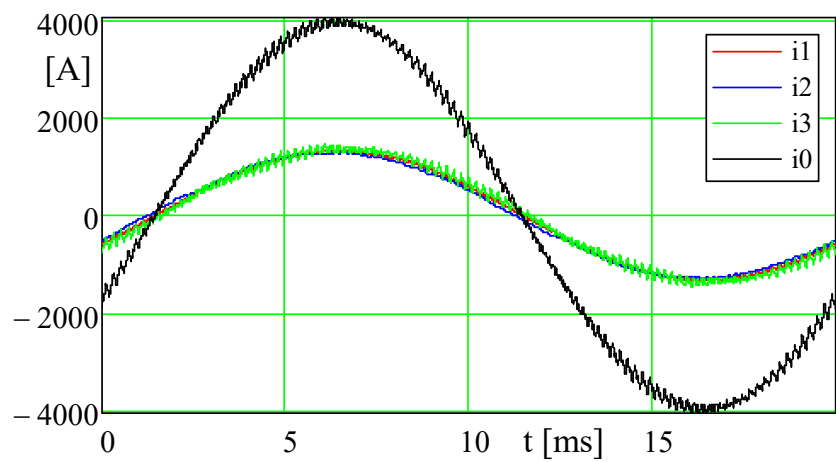

Fig. 7. Waveforms of the primary currents and of the secondary current (referred to the LV): in phase carrier signals, with $\mathrm{m}_{\mathrm{f}}=99\left(\mathrm{f}_{\text {carrier }}=4.95 \mathrm{kHz}\right)$. 
TABLE V

CurRent Fundamental, Main HaRmonics AND THD; Total Cu AND Fe LOSSES; EFFICIENCY $\left(\mathrm{m}_{\mathrm{f}}=99\right.$, IN PHASE CARRIER SIGNALS).

\begin{tabular}{|c|c|c|c|c|}
\hline Current & $\mathrm{i}_{1}$ & $i_{2}$ & $\mathrm{i}_{3}$ & $\mathrm{i}_{0}^{\prime}$ \\
\hline $\mathrm{I}_{\text {fund }}\left[\mathrm{A}_{\mathrm{rms}}\right]$ & 927 & 910 & 958 & 2792 \\
\hline $\mathrm{I}_{(\mathrm{mf}-2)} / \mathrm{I}_{\text {fund }} \quad[\%]$ & 1.38 & 0.64 & 0.64 & 1.79 \\
\hline $\mathrm{I}_{(\mathrm{mf}+2)} / \mathrm{I}_{\text {fund }} \quad[\%]$ & 1.33 & 0.59 & 0.59 & 1.72 \\
\hline $\mathrm{I}_{(2 \mathrm{mf}-1)} / \mathrm{I}_{\text {fund }}[\%]$ & 0.61 & 0.15 & 0.15 & 0.88 \\
\hline $\mathrm{I}_{(2 \mathrm{mf}+1)} / \mathrm{I}_{\text {fund }}[\%]$ & 0.61 & 0.16 & 0.16 & 0.87 \\
\hline THD I [\%] & 2.33 & 1.81 & 6.04 & 2.82 \\
\hline $\mathrm{Cu}$ losses $[\mathrm{kW}]=36.9$ & \multicolumn{2}{|c|}{ Fe losses $[\mathrm{kW}]=8.52$} & \multicolumn{2}{|c|}{ Efficiency $=98.51 \%$} \\
\hline
\end{tabular}

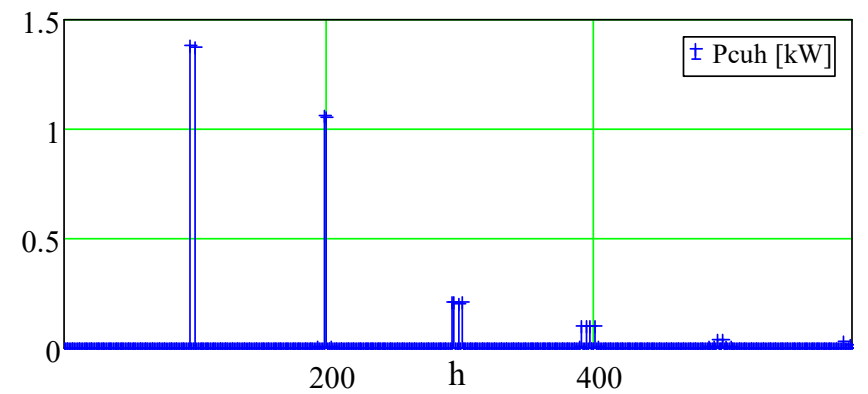

Fig. 8. Total copper losses for harmonic orders $>1$ : in phase carrier signals, with frequency ratio $\mathrm{m}_{\mathrm{f}}=99\left(\mathrm{f}_{\text {carrier }}=4.95 \mathrm{kHz}\right)$.

C. Frequency ratio $\mathrm{m}_{\mathrm{f}}=33$; in phase carrier signals.

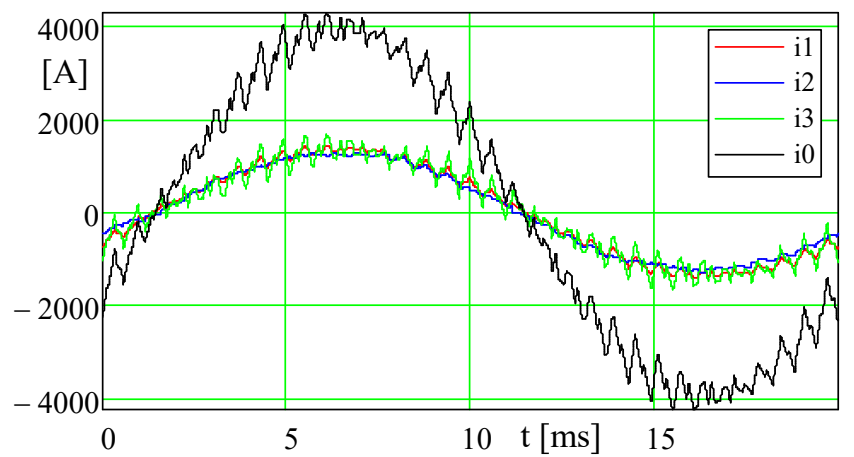

Fig. 11. Waveforms of the primary currents and of the secondary current (referred to LV): in phase carrier signals, with $m_{\mathrm{f}}=33\left(\mathrm{f}_{\text {carrier }}=1.65 \mathrm{kHz}\right)$.

TABLE VI

CurRent Fundamental, Main Harmonics And THD; Total Cu AND Fe LOSSES; EFFICIENCY $\left(\mathrm{m}_{\mathrm{f}}=33\right.$, IN PHASE CARRIER SIGNALS).

\begin{tabular}{|c|c|c|c|c|}
\hline Current & $\mathrm{i}_{1}$ & $i_{2}$ & $\mathrm{i}_{3}$ & $\mathrm{i}_{0}{ }^{\prime}$ \\
\hline $\mathrm{I}_{\text {fund }}\left[\mathrm{A}_{\mathrm{rms}}\right]$ & 955 & 890 & 951 & 2795 \\
\hline $\mathrm{I}_{(\mathrm{mf}-2)} / \mathrm{I}_{\text {fund }}[\%]$ & 4.26 & 1.67 & 11.44 & 5.63 \\
\hline $\mathrm{I}_{(\mathrm{mf}+2)} / \mathrm{I}_{\text {fund }} \quad[\%]$ & 3.64 & 1.70 & 9.83 & 4.94 \\
\hline $\mathrm{I}_{(2 \mathrm{mf}-1)} / \mathrm{I}_{\text {fund }}[\%]$ & 1.75 & 0.48 & 6.31 & 2.65 \\
\hline $\mathrm{I}_{(2 \mathrm{mf}+1)} / \mathrm{I}_{\text {fund }}[\%]$ & 1.79 & 0.68 & 6.31 & 2.60 \\
\hline $\mathrm{THD}_{\mathrm{I}}[\%]$ & 6.59 & 5.17 & 18.14 & 8.52 \\
\hline $\mathrm{Cu}$ losses $[\mathrm{kW}]=39.2$ & \multicolumn{2}{|c|}{ Fe losses $[\mathrm{kW}]=9.80$} & \multicolumn{2}{|c|}{ Efficiency $=98.40 \%$} \\
\hline
\end{tabular}

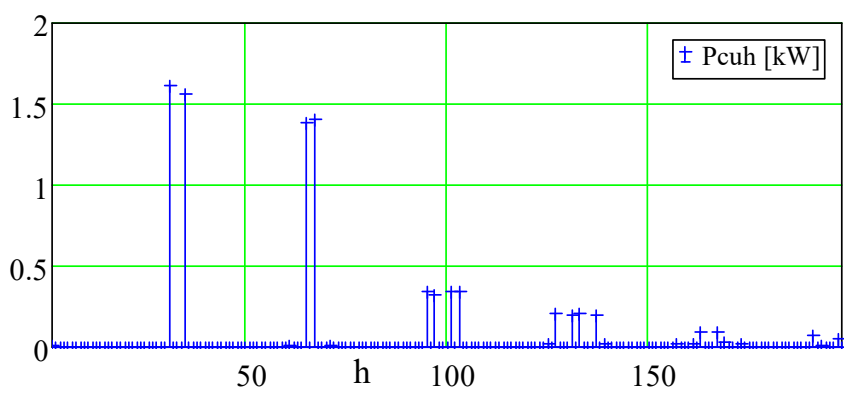

Fig. 12. Total copper losses for harmonic orders $>1$ : in phase carrier signals, with frequency ratio $\mathrm{m}_{\mathrm{f}}=33\left(\mathrm{f}_{\text {carrier }}=1.65 \mathrm{kHz}\right)$.
- the case with $\mathrm{m}_{\mathrm{f}}=33$ and displaced carrier signals is not shown, because the primary current ripple results too high (in the range $60-100 \%$ ), even if with a secondary current THD equal to $5.43 \%$ only;

- for the case $\mathrm{C}\left(\mathrm{m}_{\mathrm{f}}=33\right.$, with in phase carrier signals), the secondary current THD is higher than before $(8.52 \%)$, but with limited primary current ripple, THD and $\mathrm{Cu}$ losses; the core losses are higher than the previous ones, because of the higher flux density waveform distortion.

\section{ANALYTICAL AND FEM RESULTS COMPARISON}

In order to validate the previously developed model, some FEM simulations have been performed.

Table VII compares the binary short circuit inductances calculated analytically and by using a FEM magnetostatic 2DRZ tool: the discrepancies are within a few percent.

Table VIII compares the harmonic copper losses for the fundamental and the main harmonic orders, calculated analytically and by using a FEM eddy current $2 \mathrm{DRZ}$ tool, for the case A as an example: the results appear reasonably close.

TABLE VII

COMPARISON AMONG BINARY SHORT CIRCUIT INDUCTANCES (REF. TO LV) CALCULATED ANALYTICALLY AND BY FEM MAGNETOSTATIC 2DRZ TOOL

\begin{tabular}{|c|c|c|c|c|c|c|}
\hline $\mathrm{L}_{\text {bin.sh.c }}[\mu \mathrm{H}]$ & $\mathrm{L}_{12}$ & $\mathrm{~L}_{13}$ & $\mathrm{~L}_{10}$ & $\mathrm{~L}_{23}$ & $\mathrm{~L}_{20}$ & $\mathrm{~L}_{30}$ \\
\hline Analytical & 49.7 & 96.7 & 138.5 & 67.6 & 128.2 & 91.7 \\
\hline FEM & 51.5 & 105.5 & 158.4 & 64.8 & 125.9 & 84.4 \\
\hline
\end{tabular}

TABLE VIII

ANALYTICAL AND FEM CALCULATED COPPER LOSSES FOR THE MOST SIGNIFICANT HARMONICS $\left(\mathrm{m}_{\mathrm{f}}=99\right.$, DISPLACED CARRIER SIGNALS $)$

\begin{tabular}{|c|c|c|c|c|c|}
\hline $\mathrm{P}_{\text {cu.h.tot }}[\mathrm{kW}]$ & $\mathrm{h}=1$ & $\mathrm{~h}=\mathrm{m}_{\mathrm{f}}-2$ & $\mathrm{~h}=\mathrm{m}_{\mathrm{f}}+2$ & $\mathrm{~h}=2 \mathrm{~m}_{\mathrm{f}}-1$ & $\mathrm{~h}=2 \mathrm{~m}_{\mathrm{f}}+1$ \\
\hline Analytical & 30.43 & 3.81 & 3.74 & 2.80 & 2.79 \\
\hline FEM & 30.80 & 3.73 & 3.54 & 2.03 & 2.03 \\
\hline
\end{tabular}

\section{APPENDIX}

Starting from the binary short circuit impedances, the Starr equivalent parameters of fig. 3 are calculated as follows [12]: $\overline{\mathrm{K}}_{1}=\overline{\mathrm{Z}}_{13}+\overline{\mathrm{Z}}_{20}-\overline{\mathrm{Z}}_{12}-\overline{\mathrm{Z}}_{30} ; \overline{\mathrm{K}}_{2}=\overline{\mathrm{Z}}_{13}+\overline{\mathrm{Z}}_{20}-\overline{\mathrm{Z}}_{10}-\overline{\mathrm{Z}}_{23}$ (A1)

$$
\begin{aligned}
& \overline{\mathrm{Z}}_{\mathrm{e}}=\sqrt{\overline{\mathrm{K}}_{1} \cdot \overline{\mathrm{K}}_{2}}+\overline{\mathrm{K}}_{1} ; \quad \overline{\mathrm{Z}}_{\mathrm{f}}=\sqrt{\overline{\mathrm{K}}_{1} \cdot \overline{\mathrm{K}}_{2}}+\overline{\mathrm{K}}_{2} \\
& \bar{Z}_{\mathrm{a}}=1 / 2 \cdot\left[\overline{\mathrm{Z}}_{12}+\overline{\mathrm{Z}}_{10}-\overline{\mathrm{Z}}_{20}-\overline{\mathrm{Z}}_{\mathrm{e}} \cdot \overline{\mathrm{Z}}_{\mathrm{f}} /\left(\overline{\mathrm{Z}}_{\mathrm{e}}+\overline{\mathrm{Z}}_{\mathrm{f}}\right)\right] \\
& \overline{\mathrm{Z}}_{\mathrm{b}}=1 / 2 \cdot\left[\overline{\mathrm{Z}}_{12}+\overline{\mathrm{Z}}_{23}-\overline{\mathrm{Z}}_{13}-\overline{\mathrm{Z}}_{\mathrm{e}} \cdot \overline{\mathrm{Z}}_{\mathrm{f}} /\left(\overline{\mathrm{Z}}_{\mathrm{e}}+\overline{\mathrm{Z}}_{\mathrm{f}}\right)\right] \\
& \bar{Z}_{\mathrm{c}}=1 / 2 \cdot\left[\overline{\mathrm{Z}}_{23}+\overline{\mathrm{Z}}_{30}-\overline{\mathrm{Z}}_{20}-\overline{\mathrm{Z}}_{\mathrm{e}} \cdot \overline{\mathrm{Z}}_{\mathrm{f}} /\left(\overline{\mathrm{Z}}_{\mathrm{e}}+\overline{\mathrm{Z}}_{\mathrm{f}}\right)\right] \\
& \bar{Z}_{\mathrm{d}}=1 / 2 \cdot\left[\bar{Z}_{30}+\bar{Z}_{10}-\bar{Z}_{13}-\bar{Z}_{\mathrm{e}} \cdot \bar{Z}_{\mathrm{f}} /\left(\bar{Z}_{\mathrm{e}}+\overline{\mathrm{Z}}_{\mathrm{f}}\right)\right] \\
& \mathrm{R}_{\mathrm{q}}=\mathfrak{R e}\left(\overline{\mathrm{Z}}_{\mathrm{q}}\right) ; \mathrm{L}_{\mathrm{q}}=\mathfrak{I m}\left(\overline{\mathrm{Z}}_{\mathrm{q}}\right) / \omega, \mathrm{q}=\mathrm{a}, \mathrm{b}, \ldots, \mathrm{f}
\end{aligned}
$$

By referring to the sizes of fig. 1, the parameters involved in the leakage inductance (1) can be evaluated as follows:

$$
\begin{gathered}
\mathrm{k}_{\mathrm{L}}=\mathrm{N}_{\mathrm{LV}}^{2} \cdot \mu_{0} / \mathrm{h}_{\mathrm{a}} \\
\mathrm{p}_{12}=2 \pi \cdot \mathrm{r}_{12}=2 \pi \cdot\left(\mathrm{D} / 2+\mathrm{d}_{1}+\mathrm{a}_{1}+\mathrm{b}_{12} / 2\right) \\
\mathrm{p}_{13}=2 \pi \cdot \mathrm{r}_{13}=2 \pi \cdot\left[\mathrm{r}_{12}+\left(\mathrm{a}_{2}+\mathrm{b}_{23}\right) / 2\right] \\
\mathrm{p}_{10}=2 \pi \cdot \mathrm{r}_{10}=2 \pi \cdot\left[\mathrm{r}_{13}+\left(\mathrm{a}_{3}+\mathrm{b}_{30}\right) / 2\right] \\
\mathrm{p}_{23}=2 \pi \cdot \mathrm{r}_{23}=2 \pi \cdot\left(\mathrm{D} / 2+\mathrm{d}_{1}+\mathrm{a}_{1}+\mathrm{b}_{12}+\mathrm{a}_{2}+\mathrm{b}_{23} / 2\right) \\
\mathrm{p}_{20}=2 \pi \cdot \mathrm{r}_{20}=2 \pi \cdot\left[\mathrm{r}_{23}+\left(\mathrm{a}_{3}+\mathrm{b}_{30}\right) / 2\right]
\end{gathered}
$$




$$
\begin{aligned}
& \mathrm{p}_{30}=2 \cdot \pi \cdot\left[\mathrm{r}_{20}+\left(\mathrm{b}_{23}+\mathrm{a}_{3}\right) / 2\right] \\
& c_{12}=b_{12}+\left(a_{1}+a_{2}\right) / 3 \\
& c_{13}=b_{12}+a_{2}+b_{23}+\left(a_{1}+a_{3}\right) / 3 \\
& c_{10}=b_{12}+a_{2}+b_{23}+a_{3}+b_{30}+\left(a_{1}+a_{0}\right) / 3 \\
& c_{23}=b_{23}+\left(a_{2}+a_{3}\right) / 3 \\
& c_{20}=b_{23}+a_{3}+b_{30}+\left(a_{2}+a_{0}\right) / 3 \\
& c_{30}=b_{30}+\left(a_{3}+a_{0}\right) / 3 \\
& \mathrm{~K}_{\mathrm{R}}\left(\sigma_{\mathrm{R}}\right)=1-\left(1-\mathrm{e}^{-\sigma_{\mathrm{R}}}\right) / \sigma_{\mathrm{R}} \\
& \sigma_{\mathrm{R} 12}=\pi \mathrm{h}_{\mathrm{a}} /\left(2 \cdot \mathrm{b}_{12}+\mathrm{a}_{1}+\mathrm{a}_{2}\right) \\
& \sigma_{\mathrm{R} 13}=\pi \mathrm{h}_{\mathrm{a}} /\left[2 \cdot\left(\mathrm{b}_{12}+\mathrm{a}_{2}+\mathrm{b}_{23}\right)+\mathrm{a}_{1}+\mathrm{a}_{3}\right] \\
& \sigma_{\mathrm{R} 10}=\pi \mathrm{h}_{\mathrm{a}} /\left[2 \cdot\left(\mathrm{b}_{12}+\mathrm{a}_{2}+\mathrm{b}_{23}+\mathrm{a}_{3}+\mathrm{b}_{30}\right)+\mathrm{a}_{1}+\mathrm{a}_{0}\right] \\
& \sigma_{\mathrm{R} 23}=\pi \mathrm{h}_{\mathrm{a}} /\left(2 \cdot \mathrm{b}_{23}+\mathrm{a}_{2}+\mathrm{a}_{3}\right) \\
& \sigma_{\mathrm{R} 20}=\pi \mathrm{h}_{\mathrm{a}} /\left[2 \cdot\left(\mathrm{b}_{23}+\mathrm{a}_{3}+\mathrm{b}_{30}\right)+\mathrm{a}_{2}+\mathrm{a}_{0}\right] \\
& \sigma_{\mathrm{R} 30}=\pi \mathrm{h}_{\mathrm{a}} /\left(2 \cdot \mathrm{b}_{30}+\mathrm{a}_{3}+\mathrm{a}_{0}\right) \\
& \text { The average coil perimeters are expressed by: } \\
& \mathrm{p}_{1}=2 \pi \cdot \mathrm{r}_{1}=2 \pi \cdot\left(\mathrm{D} / 2+\mathrm{d}_{1}+\mathrm{a}_{1} / 2\right) \\
& \mathrm{p}_{2}=2 \pi \cdot \mathrm{r}_{2}=2 \pi \cdot\left[\mathrm{r}_{1}+\mathrm{b}_{12}+\left(\mathrm{a}_{1}+\mathrm{a}_{2}\right) / 2\right] \\
& \mathrm{p}_{3}=2 \pi \cdot \mathrm{r}_{3}=2 \pi \cdot\left[\mathrm{r}_{2}+\mathrm{b}_{23}+\left(\mathrm{a}_{2}+\mathrm{a}_{3}\right) / 2\right] \\
& \mathrm{p}_{0}=2 \pi \cdot \mathrm{r}_{0}=2 \pi \cdot\left[\mathrm{r}_{3}+\mathrm{b}_{30}+\left(\mathrm{a}_{3}+\mathrm{a}_{0}\right) / 2\right]
\end{aligned}
$$

The additional loss coefficients in (4)-(9) are based on the following auxiliary functions:

$$
\begin{array}{r}
\varphi_{\mathrm{a}}(\xi)=\xi[\sinh (2 \xi)+\sin (2 \xi)] /[\cosh (2 \xi)-\cos (2 \xi)](\mathrm{A} 32) \\
\psi_{\mathrm{a}}(\xi)=2 \xi[\sinh (\xi)-\sin (\xi)] /[\cosh (\xi)+\cos (\xi)](\mathrm{A} 33)
\end{array}
$$

The auxiliary variable $\xi$ for the $\mathrm{LV}$ and HV coils equal:

$$
\begin{aligned}
& \xi_{\mathrm{LV}}(\mathrm{f})=\mathrm{w}_{\mathrm{pLV}} \cdot \sqrt{\pi \cdot \sigma_{\mathrm{cu}} \cdot \mathrm{f} \cdot \mu_{0}} \\
& \xi_{\mathrm{HV}}(\mathrm{f})=\mathrm{w}_{\mathrm{pHV}} \cdot \sqrt{\sigma_{\mathrm{cu}} \cdot \pi \cdot \mathrm{f} \cdot \mu_{0} \cdot\left(\mathrm{N}_{\mathrm{D}} \cdot \mathrm{h}_{\mathrm{pHV}}\right) / \mathrm{h}_{\mathrm{a}}}
\end{aligned}
$$

where: $\mathrm{w}_{\mathrm{pLV}}=1.12 \mathrm{~mm}$ and $\mathrm{w}_{\mathrm{pHV}}=1.70 \mathrm{~mm}$ are the radial width of the LV and $\mathrm{HV}$ plates, $\mathrm{N}_{\mathrm{D}}$ is the $\mathrm{N}^{\circ}$ of $\mathrm{HV}$ disks and $\sigma_{\mathrm{cu}}=\rho_{\mathrm{cu}}{ }^{-1}$ (see Table I).

The additional loss coefficients for the winding 1, 2, 3, 0 are:

$$
\begin{aligned}
& \mathrm{k}_{\mathrm{ai}}=\varphi_{\mathrm{a}}\left(\xi_{\mathrm{LV}}\right)+\frac{\left(\mathrm{N}_{\mathrm{pcLV}} / 2\right)^{2}-1}{3} \cdot \psi_{\mathrm{a}}\left(\xi_{\mathrm{LV}}\right), \quad \mathrm{i}=1,2,3 \\
& \mathrm{k}_{\mathrm{a} 0}=\varphi_{\mathrm{a}}\left(\xi_{\mathrm{HV}}\right)+\frac{\left(\mathrm{N}_{\mathrm{pcHV}} \cdot \mathrm{N}_{\mathrm{HV}} / \mathrm{N}_{\mathrm{D}}\right)^{2}-1}{3} \cdot \psi_{\mathrm{a}}\left(\xi_{\mathrm{HV}}\right), \\
& \mathrm{k}_{\mathrm{a} 2 \mathrm{p}}=\mathrm{k}_{\mathrm{a} 3 \mathrm{p}}=\left(\mathrm{N}_{\mathrm{pcLV}} / 2\right)^{2} \cdot \psi_{\mathrm{a}}\left(\xi_{\mathrm{LV}}\right) .
\end{aligned}
$$

\section{CONCLUSION}

Some design and modeling aspects of a four winding transformer, to be used as an interface among multi-module inverters and mains, have been analyzed.

The equivalent network parameters have been identified, based on all the binary short circuit impedances; besides, the copper and core losses have been estimated taking into account skin effect and harmonic eddy current losses in iron.

A few inverter feeding conditions have been simulated, at different carrier frequency and carrier signal displacement, and the transformer performances have been compared.
A few FEM simulations have been performed, to validate the circuit model.

Different coil dispositions will be analyzed in the future, aimed to increase the leakage inductances seen among primary coils. Moreover some experimental activity will be conducted on suited scaled prototypes.

\section{REFERENCES}

[1] M.B. Wafaa, and L-A. Dessaint, "Approach to dynamic voltage stability analysis for DFIG wind parks integration," IET Renewable Power Generation, Vol. 12, N. 2, 2018, pp 190 - 197.

[2] C. Ditmanson, P. Hein, S. Kolb, J. Mölck, and S. Bernet, "A New Modular Flux-Switching PM Drive for Large Wind Turbines," IEEE Trans. on Ind. Appl., Vol. 50, N. 6, Nov./Dec. 2014, pp. 3787-3794.

[3] Y.-S. Park, M.-M. Koo, S.-M. Jang, J.-Y. Choi and D.-J. You, "Performance Evaluation of Radial- and Axial-Flux PM Wind Power Generators With Mechanical Energy Storage System," IEEE Trans. on Energy Conversion, 2015, Vol. 30, N. 1, pp. 237 - 245.

[4] O. Alizadeh and A. Yazdani, "A Control Strategy for Power Regulation in a Direct-Drive WECS With Flexible Drive-Train," IEEE Trans. on Sustainable Energy, 2014, Vol. 5, N. 4, pp. $1156-1165$.

[5] D. Zhou and F. Blaabjerg, "Optimized Demagnetizing Control of DFIG Power Converter for Reduced Thermal Stress during Symmetrical Grid Fault," IEEE Trans. on Power Electronics, 2018, Vol. PP, N. 99 pp. 1 - 1.

[6] E. Levi, "Multiphase Electric Machines for Variable-Speed Applications," IEEE Trans. on Industrial Electronics, 2008, Vol. 55, N. 5, pp. $1893-1909$.

[7] I. Gonzalez-Prieto, M. J. Duran, H.S. Che, E. Levi, M. Bermúdez, F. Barrero, "Fault-Tolerant Operation of Six-Phase Energy Conversion Systems With Parallel Machine-Side Converters," IEEE Trans on Power Electronics, 2016, Vol. 31, n. 4, pp. 3068 - 3079.

[8] T. Husain, I. Hasan; Y. Sozer; I. Husain; E. Muljadi, "Design of a Modular E-Core Flux Concentrating Transverse Flux Machine," IEEE Trans. on Industry Applications, 2018, Vol. pp, N. 99, pp. 1 - 1.

[9] A. Di Gerlando; K. ElShawarby; G. M. Foglia; R. Perini: "DC side current and torque ripples reduction in multi modular PMSG for wind applications", XXII Int. Conf. on Electrical Machines (ICEM), 2016, pp. 252-258.

[10] A. Di Gerlando; K. ElShawarby; M. Iacchetti, G. M. Foglia; R. Perini: "DC Current and Torque Ripple Mitigation in Modular PMSGs Drives for Multi-MW WECS with Linear PWM Inverter Modulation," XXIII Int. Conf. on Electrical Machines (ICEM), 2018.

[11] A. Di Gerlando; K. ElShawarby; G. M. Foglia: "Torque and Current Ripple Reduction in PM Generator based Multi Modular - Multi MW WECSs with Extended PWM Inverter Modulation," XXIII Intern. Conf. on Electrical Machines (ICEM), 2018.

[12] F. M. Starr: "An equivalent circuit for the four winding transformers", General Electric Review, March 1933, Vol. 36, n. 3, p. 150.

\section{BIOGRAPHIES}

Antonino Di Gerlando received his MS degree in electrical engineering from the Politecnico di Milano, Italy, in 1981. Currently, he is a Full Professor at the Department of Energy at Politecnico di Milano. Fields of interest: design and modeling of electrical machines, converters and drive systems. He is a senior member of IEEE and a member of the Italian Association of the Electric and Electronic Engineers (AEI).

Khaled EIShawarby received his MS degree in electrical engineering at Politecnico di Milano, Milano, Italy 2016. Currently, he is a PhD student in Electrical Engineering at Politecnico di Milano, Italy. His interests are in power electronics and electrical machines.

Giovanni Maria Foglia received his MS degree and the $\mathrm{PhD}$ in electrical engineering at Politecnico di Milano, Milano, Italy, in 1997 and 2000.

Currently, he is an Assistant Professor at the Department of Energy at Politecnico di Milano, and his main field of interest is the analysis and design of PM electrical machines.

Roberto Perini (M'10) received his MS degree and the $\mathrm{PhD}$ in electrical engineering from the Politecnico di Milano, Milano, Italy.

Currently, he is an Associate Professor at the Department of Energy at Politecnico di Milano. His interests are in the design and modeling of electrical machines and power electronics. 